\title{
BIBLIOGRAFIA
}

\section{O CATÁLOGO DA COLEÇÃO GREENLEE (*).}

\author{
ELISABETH CONCETA MIRRA \\ Historiógrafa do Setor de Documentação do Depar- \\ tamento de História da Faculdade de Filosofia, Le- \\ tras e Ciências Humanas da Universidade de São \\ Paulo.
}

Entre as diversas áreas de trabalho do Setor de Documentação do Departamento de História da Faculdade de Filosofia, Letras e Ciências Humanas da Universidade de São Paulo, para constituir um núcleo formativo de fontes históricas, destaca-se a Bibliográfica, tanto nacional como internacional. E, de acordo com um dos itens do seu regulamento operacional, se torna indispensavel reunir catálogos de arquivos, museus e bibliotecas, obter atlas e mapas históricos para facilitar a consulta documentária e amparar a programação de pesquisa.

Aliás, obedecendo esta muito util finalidade, o Prof. Frédéric Mauro, na sua permanência de dois meses em 1970, no Setor de Documentação, ampliou o já existente fichário bibliográfico sobre o Brasil e orientou a criação de um fichário seletivo para a América Latina, com anotações explicativas, sempre que possíveis.

Com este objetivo, já foi iniciada a catalogação do Handbook of Latin AmericanStudies - Biblioteca do Congresso, Washington - e se providenciaram contatos com entidades afins para obtenção de catálogos de arquivos, bibliotecas e museus.

Em 22 de setembro de 1970, enviamos uma circular à Newberry Library, de Chicago, USA, solicitando os Catálogos Ayer-Hispanic American Section e Greenlee Collection. Somente no dia 5 de junho de 1972 obtivemos resposta, e o seu diretor, Frederick Holden Hall desculpando-se pela demora, explicou que as publicações pedidas são

$(*)$. Catologue of the Greenlee Collection. The Newberry Library. Chicago. Volume I. A-Lim. G. K. Hall \& Co., 70 Lincoln Street. Boston. Massachusetts, 1970. 
de certa envergadura e muito caras: o Catálogo Ayer constituído de 16 volumes e 2 suplementos e o Greenlee de 2 volumes grandes. Por isso, sugeria a sua aquisição através do programa de ajuda interamericana.

Entretanto, o Sr. Frederick Holden Hall, gentilmente nos presenteou com uma cópia da introdução por ele feita ao Catálogo da Coleção Greenlee de História e Literatura Portuguesas, da Newberry Library, publicada por G. K. Hall \& Co., Boston, Massachusetts. Aconselhou-nos a sua tradução e publicação. na Revista de História, como um auxílio informativo bibliográfico e afirmou-nos constituir o Catálogo um meio de pesquisa importante para o estudante no campo da literatura e história portuguesas.

O Catálogo Greenlee, publicado em 1953 sob a orientação da Catalogadora Miss Doris Varner Welsh continua sendo ampliado e, atualmente reproduz aproximadamente 31.000 fichas $(10 \times 14)$ com as seguintes observações: autor, título, registro de entrada, comentários das obras adquiridas, relacionados nestes últimos 70 anos (conforme modelo anexo).

A introdução ao Catálogo Greenlee, traduzida e transcrita abaixo, mostra indiscutivelmente o valor extraordinário da obra, merecedora de sua aquisição pelo Setor de Documentação do Departamento de História.

Esse Catálogo oferece auxílios inestimáveis aos pesquisadores nacionais e estrangeiros nos estudos dos assuntos luso-brasileiros, do século XV até os nossos dias, résaltando em particular os subsídios que apresentam da época dos Descobrimentos.

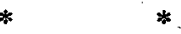

$*$

Catalogue of the Greenlee Collection, The Newberry Library.

Greenlee

p4891 LOPEZ DE VARGAS MACHUCHA, TOMAS, 1731-1802.

L86 Mapa general del reyno de Portugal; comprehende sus provin1778 cias, corregimientos, oidorias, proveedurias, concejos, cotos, \&c ... por Tomás Lopez. Madrid, 1778.

map. $147 \times 86 \mathrm{~cm}$.

Scale: about 3 Spanish leagues to the inch. 


\begin{abstract}
Greenlee
4504 AFONSO, GREGORIO.

P855 Arrenegos que fez Gregorio Affonso criado do Bispo de Evora, com outros arrenegos de Gil Vicente de Lisboa, novamente impressos. Esta conforme com o original. Em S. Eloy de Lisboa a 4. de dezembro de 1620. M. Vicente da Resurreição. [Lisboa, Domingos Carneyro] 1649.
\end{abstract}

[8] p. $20 \mathrm{~cm}$.

Caption title.

Reprinted from Garcia de Resende's Cancioneiro geral.

7304

ICN

Greenlee

4583 AYALLA, FREDERICO DINIZ D'.

I55 Vasco da Gama. Quando partiu? Problema chronologico posto.

G2 Alemquer, H. Campeão \& C.a, 1898.

A97

1898

4305

xiii, 59 p. $24 \mathrm{~cm}$.

SHELF CARD

ICN $50-5340$

\title{
Greenlee
}

4552 JESUITS. Letters from missions (The East).

J5 Nvovi avisi dell'India di Portogallo, riceuuti dalli reuerendi padri

J58 della Compagnia di Giesv, tradotti dalla lingua apagnuola nell'ita-

1568 liana. [Vinetia, M. Tramezzino] 1568.

[4], $591.15 \mathrm{~cm}$.

Title vignette (printer's device).

Imperfect: verso of leaf 56 covered with blank leaf; leaves 57-59 wanting.

With this is bound their Nrovi avisi delle Indie di Portogallo ... [1565].

1712

SHELF CARD

ICN $49-2450$

Greenlee

4558 RESENDE, ANDRE DE, 1498-1573.

B43 Libri quatuor de antiquitatibus Lusitaniae. Accessit liber quintus 1593 de antiquitate municipij Eborensis, ab eodem Vasconcello conscriptus, quo etiam autore, secundus tomus quinque alios libros continens, cito, deo opt. max. fauente, in lucem prodibit. Ebora, Excudebat Burgensis, 1593 .

[33], 25946, [20] p. $28 \mathrm{~cm}$.

"Vita L. Andreae Resende, autore Iacobo Mencetio Vasconcello": p. [12-18] (1st group). 


\author{
Greenlee \\ 4559 MARQUES, ANTÓNIO HENRIQUE RODRIGO DE OLIVEIRA. \\ M357 Ensaios de história medieval portuguesa. Lisboa, Portugália \\ 1965 Editôra [1965]. \\ 307 p. fold. map. $22 \mathrm{~cm}$.
}

Contents. - Prefácio. - Ideário para uma história económica de Portugal na Idade Média. - A população portuguesa nos fins do século XIII. - A pragmática de 1340. - Estratificação económico-social de uma vila portuguesa da Idade Média. - Navegação prussiana para Portugal nos princípios do século XV. - Notas para a história da feitoria portuguesa na Flandres, no século XV. - A moeda portuguesa durante a Idade Média.

Greenlee

Manuel, king of Portugal, 1469-1521.

4604 Epistola de el-rei D. Manoel ao papa Julio II de 12 de junho M29 de 1505. [Ponta Delgada, ilha de S. Miguel, Imprensa do Diário 1906 dos Açores, 1906]

1 p. L, [18] p. $22 \mathrm{~cm}$.

Title vignette: Cost of arms of Portugal.

Caption title: Epistola [etc.] respondendo ao breve de 26 de agosto de 1504 .

"Breve do papa Julio II remettendo a el-rei D. Manoel copia das cartas em que o sultão de Babylonia ameaçava destruir os logares santos, principalmente por causa das conquistas dos Portugueses, para que el-rey veja o que a Santa Sé lhe ha de responder": p. [1-2] (In Latin; dated "die XXVI augusti MDCIII").

"D'este opusculo foram impressos apenas sessenta exemplares destinados a offertas".

(Continued on next card)

6930

[42b1]

$7-21188$

Greenlee

4644.9 ABRANTES, LAURE SAINT-MARTIN (PERMON) JUNOT, A16 duchesse d', 1784-1838.

A16 Souvenirs d'une ambassade et d'un séjour en Espagne et en 1837 Portugal, de 1808 a 1811.

Paris, Ollivier, 1837.

$2 \mathrm{v} .21 \mathrm{~cm}$. 


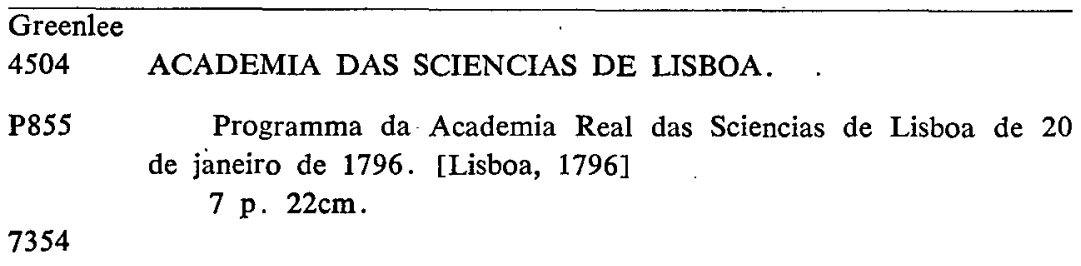

Estas fichas foram selecionadas ao acaso, somente para mostrar o formato.

Introdução ao Catálogo da Coleção Greenlee.

Nos últimos anos do século passado, quando Wiliam Brooks Greenlee estudou história com o Prof. Henry Morse Stephens, da Universidade Cornell, desenvolveu pela nação portuguesa, sua evolução histórica e os resultados culturais obtidos, um interesse que se estendeu por toda sua vida, tanto em sua terra como além-mar. Por algum tempo o jovem Greenlee, de acordo com informações, teve mesmo a esperança de dedicar sua vida especializando-se em pesquisas neste campo. Mas o peso das responsabilidades que tinha com os grandes interesses de negócios de família, tornaram esta esperança impraticável, se bem que teve algum consolo e muito estímulo intelectual numa grande viagem que fez ao redor do mundo, da qual toda a família Greenlee participou. $O$ jovem e frustrado historiador foi capaz de seguir os vestígios dos pioneiros portugueses em muitas partes remotas do mundo, especialmente no Oriente, onde, segundo hábito altamente vitoriano, toda a família Greenlee posou para o fotógrafo - sentada em seus calcanhares, no chão, à moda japonesa, vestida com resplandecentes quimonos!

O controle dos interesses comerciais da família, consumia a maior parte das energias deste eminente chicagano, mas, mesmo assim, achava tempo para as responsabilidades cívicas. Destas, nenhuma estava mais perto de seu coração do que a sua participação como membro do Board of Trustees of the Newberry Library. Uma das maiores atrações que encontrou nesta biblioteca foi a coleção de Edward E. Ayers - Americana e American Indians. Nesta estavam incluídos centenas de volumes relativos à história portuguesa e sua expansão além-mar, e, particularmente, à história do maior dos territórios portugueses: - o Brasil.

Tendo começado quando ainda jovem a comprar livros, nunca mais parou. Além disso, com o passar do tempo, aquela sua vontade de tanto tempo, de dedicar-se à pesquisas, aumentou ainda mais. Conseguindo organizar satisfatoriamente os interesses comerciais, foi capaz de dar um grande passo para atingir sua me- 
ta: - dedicando-se então com maior afinco à compra de livros. Com muito cuidado programou uma série de viagens à Europa, tendo visitado sistematicamente vendedores de livros em muitas cidades fora de mão, bem como em capitais nacionais e de províncias. Os mapas em que traçou suas rotas, elaborando um curso tão cuidadosamente quanto um navegador, são testemunhas da minuciosidade no preparo de seu trabalho e da sua aguda percepção, quanto às possibilidades inerentes à remotas e obscuras livrarias.

O seu relacionamento com Edward Ayer - que também consultava constantemente a Coleção Ayer - sua amizade com a Dra. Ruth Lapham Butler, que custodiava a referida coleção e a quem fazia consultas, tornaram-no um "bibliotecomaníaco", num grau incomum, até mesmo para um bibliotecário profissional. Embora sua coleção fosse ainda relativamente pequena, decidiu doar seus livros portugueses à Newberry, o que fez em 1937, estipulando sabiamente que fossem guardados juntamente com a grande coleção Ayer, a qual continha muitos volumes documentando o desenvolvimento da Cartografia e Ciências Náuticas portuguesas, bem como a implantação de colônias imperiais portuguesas ao redor do mundo, especialmente no Brasil.

Apesar desta sua coleção cobrir especialmente toda a história e cultura portuguesas até o início de século XIX, Greenlee teve seu interesse voltado principalmente para as memoráveis façanhas de seus corajosos navegantes. Isso tornou-se claro em 1938, quando apareceu em prestigiosa publicação do The Hakluyt Society. The voyage of Pedro Alvares Cabral to Brazil and India from comtemporary documents and narratives, traduzido com introdução e notas, por William Brooks Greenlee (London, 1938; Second Series, No LXXXI). Foi esta uma magnífica estréia em pesquisa histórica que nem mesmo um historiador profissional poderia esperar. As maravilhosas revelações e os lucros imensos que resultaram da viagem pioneira de Vasco da Gama, encorajaram o monarca portugues a formar uma segunda armada. A esta, sob o comando de Cabral, coube o grande destino de descobrir o Brasil. Estudiosos, naturalmente, há muito tempo estavam a par destes documentos, que de várias maneiras se referiam a este acontecimento histórico. Porém, tais documentos estavam dispersos em várias publicações, nem sempre encontradas, mesmo nas grandes bibliotecas. Desta grande quantidade de documentos, Greenlee selecionou cuidadosamente os mais reveladores, traduzindo o portugues arcaico dos séculos XV e XVI, para 
o ingles. Acrescentou uma impressionante introdução de sua autoria e forneceu numerosas notas repletas de informações úteis.

Este primeiro trabalho foi seguido de $A$ descriptive bibliography of the history of Portugal na The Hispanic American His. torical Review (Vol. 20, $\mathrm{n}^{\circ}$ 3, agosto, 1940 - a primeira de uma série distinta de artigos examinando os anos críticos da implantação de colônias portuguesas ao longo da costa brasileira: The first half century of Brazilian history (Mid-America, Vol. $25, \mathrm{n}^{\circ} 2,1943$ ); "The captaincy of the second Portuguese voyage to Brazil, 1501/1502" (The Americas, Vol. II, $\mathrm{n}^{\circ}$ 1, julho, 1945) e The background of Brazilian history, (ibid., vol. II, $\mathrm{n}^{\circ}$ 2, outubro, 1945 .

Durante todo o tempo em que satisfazia sua necessidade de pesquisar e escrever, Greenlee reduzia cada vez mais o tempo que dedicava aos negócios. Sem um ajustamento assim, naturalmente, um ativo homem de negócios - mesmo possuidor de uma mente analítica, e, linguisticamente bem equipado - não poderia ter produzido uma obra tão respeitável. Mas a compra de livros não havia sido esquecida e para melhor dedicar-se a ela, montou um escritório na Biblioteca Newberry, nos recintos da Coleção Ayer. Nestes, auxiliado e encorajado pela erudição e experiência bibliográfica da Dra. Butler, funcionou não somente como generoso doador de uma coleção de rápido crescimento, mas também como seu bibliógrafo. Acompanhado pela sra. Greenlee (cuja admiração pelos trabalhos do marido levaram-na a doar a coleção, após sua morte) e pela Dra. Butler, fez várias visitas mais a Portugal, vasculhando estoques de livrarias, em cidades, cidadesinhas e vilas.

Quando Sociedadés Culturais e Instituições Acadêmicas prestaram honras a Greenlee, como o fizeram: - ele foi Membro da Sociedade de Geografia de Lisboa, da Real Sociedade Geográfica, do Instituto Real de Filosofia, da Sociedade Geográfica Americana, da Sociedade de Halkluyt, e Membro Honorário do Instituto Histórico e Geográfico de São Paulo - o fizeram em reconhecimento a um homem que não se satisfazia apenas com os benefícios dados a uma grande biblioteca de pesquisas, mas que teve seus trabalhos coroados de êxito nos últimos anos, em grau nunca esperado e raramente encontrado num homem de negócios. Seu interesse pelos estudos luso-brasileiros não diminuiu, tendo encontrado uma maneira eficaz de promovê-los mais ainda: em 1950 uniu-se a um grupo de estudiosos, que pensavam como ele, de Portugal, Brasil, Europa e Américas, para introduzir 
a primeira das brilhantes e fecundas séries de palestras internacionais sobre estudos luso-brasileiros, assistindo ao conclave inicial na biblioteca do Congresso em Washington, naquele ano. Nesse mesmo ano, o Governo portugues, muito acertadamente, entregou a Greenlee a comenda de maior mérito e serviços no mundo dos estudiosos, nomeando-o Superior da Ordem de Sto. Tiago do século XIII.

Quase no fim de sua vida, Greenlee recebeu de Portugal mais uma distinção. Sua compilação e estudo (para a Hakluyt Society, 1938) dos documentos importantes da viagem de Cabral de 1500 , foram traduzidos por distinguido estudioso e publicados em Oporto, em 1952 - A viagem de Pedro Alvares Cabral ao Brasil e à India pelos documentos e relações coevas. Introdução e notas de William Brooks Greenlee. Tradução de Antonio Alvaro Dória. Apesar de que estes documentos estivessem muito dispersos, não sendo encontrados em muitas bibliotecas, os estudiosos os conheciam - mesmo aqueles que ainda estavam só manuscritos. O trabalho de Dória não foi feito necessariamente para ser divulgado entre portugueses, brasileiros e outros estudiosos, fora do mundo anglo-saxônico, mas sim foi um meio de fazer amplamente conhecida a riqueza de dados interpretativos que Greenlee nele colocou. No ano seguinte (1953), morreu, com 81 anos, depois de uma vida exaustiva como homem de negócios, eminente chicagano, benfeitor, curador da Biblioteca Newberry e estudioso. Aproximadamente duas décadas após sua morte, já fícou evidente que seu nome perduraria como o doador desta coleção da História Portuguesa e Literatura e como o historiador dos maiores feitos de Portugal em sua notável expansão além-mar.

No verdadeiro sentido foi Greenlee quem primeiro custodiou sua coleção, mas, após sua morte, o seu desenvolvimento, na maior parte, foi o principal trabalho da Dra. Ruth Lapham Butler, grande amiga e colaboradora de tantos anos. Como Greenlee havia desejado que seus livros fossem colocados juntos à Coleção Ayer - com seu grande acervo de "Brasiliana" Colonial foi natural que a Dra. Butler custodiasse ambas as coleções. Nesta condição ideal, ele pôde aumentá-las, formando um todo coerente de suas partes interdependentes, presidindo a Coleção Greenlee durante os anos mais importantes de sua formação e, aposentando-se somente em 1961.

Unindo os seus conhecimentos históricos à sua obstinação de homem de negócios, concentrou-se em formar uma coleção de textos importantes, algumas vezes em detrimento de raridades bi- 
bliográficas de grande valor. De forma nenhuma teve a intenção de concorrer com a Coleção Palha, que tinha livros raros, da Universidade de Harvard. Da mesma maneira, através da Coleção Ayer, forneceu grande parte de dados básicos para a história de viagens e explorações e para o desenvolvimento cartográfico, geográfico e ciências náuticas, bem como para a história e cultura dos aborígenes americanos. No entanto, livros raros constam na Coleção Greenlee, que já figuravam quando o doador ainda vivia, pois, tendo trabalhado com documentos dos séculos XV e XVI, apercebeu-se da importância das primeiras e antigas edições. Mas, a ênfase maior na aquisição de livros raros, foi uma característica oportuna na administração da Dra. Butler, refletindo o fato de que a coleção era então bem fundamentada em trabalhos básicos, apesar de sua grande diversidade (pouco existia que escapasse à definição e literatura de Greenlee). O acima exposto é melhor ilustrado através de um estudo das páginas que seguem e sua comparação com o Dictionary Catalog of the Edward $E$. Ayer Collection of Americana and Americans Indians na The Newberry Library (16 vols., Boston, G. K. Hall \& Co., 1961, \& First Supplement, 2 vols., 1970.

Se Greenlee foi responsável pela organização da Coleção, determinando seu amplo campo cultural, a Dra. Butler deve ser considerada como orientadora de sua expansão, tendo incrementado sua profundidade bibliográfica com rara sabedoria e agudeza. E mera justiça reconhecer que sua contribuição à coleção só foi superada pela do seu fundador. Uma crítica à sua obra - que vale a pena ser lida 20 anos após sua publicação - pode ser encontrada no artigo C. R. Boxer's: The William B. Greenlee Collection: 1. The Collector. II The Collection in "The Bulletin of The Newberry Library", Second series, $n^{\circ}$ 6, May, 1951 pages $167 / 178$.

Doris Varner Welsh que foi por muitos anos a catalogadora de ambas as coleções, Ayer e Greenlee, foi também a compiladora do bastante conbecido e muito admirado Guia, A Catalog of The William B. Greenlee Collection of Portuguese History and Literature and the Portuguese materials in the Newberry Library (Chicago, 1953,342 p.). Este foi um trabalho de valor único em vários aspectos. Tendo sido compilado pela mesma pessoa que havia catalogado todo o seu conteúdo, refletia sua familiaridade com o mesmo e o grande conhecimento que tinha adquirido. O catálogo Welsh era particularmente atraente por ser um guia classificado, contendo seções dedicadas a Trabalhos Gerais de Referência, His- 
tória Política de Portugal, História Eclesiástica, História Econômica, Militar, Cultural e Local de Portugal, etc., e seções classificadas sobre a História de Colônias Individuais Portuguesas. Deve ser salientado que a considerável parte sobre o Brasil (n's. 3231-4522) reflete a segunda parte do título do catálogo, pois introduz principalmente livros que pertencem à Coleção Ayer. O guia Welsh é também importante, mesmo após quase 20 anos de sua publicação, porque leva o estudante a muitas obras portuguesas existentes na Newberry Library, mas que não pertencem nem a Greenlee, nem a Ayer, e por este motivo não mencionados em seus catálogos impressos, publicados por G. K. Hall \& Co.. Para exemplificar isto, posso mencionar o Dicionário Castelhano e Portugues de Bluteau (Lisboa, 1721) que consta em nossa Coleção Bonaparte, e do mesmo autor, Vocabulário Portugues, e Latino... (Coimbra, 1712-1721) que se encontra na nossa Coleção Geral. Este bibliógrafo tão frequentemente recebe pedidos de exemplares do catálogo Welsh, que bem pode aproveitar esta ocasião para afirmar que o mesmo não está mais sendo impresso. A publicação do presente trabalho, refletindo o tipo de dicionário do registro do catálogo da Coleção Greenlee, que requer dos usuários que procurem pelo regiśtro de assuntos em lugar das seções classificadas, estabelecidas por Welsh, certamente concorda com a reimpressão de seu catálogo publicado em 1953. No entanto, deve-se salientar que um eventual usuário da Cóleção Greenlee estaria bem aconselhado se consultasse o catálogo de Welsh nas bibliotecas, pois o mesmo representa um guia sem paralelo para o conteúdo geral da coleção, bem como, pondo em destaque muitas obras fora da coleção, mas que ainda podem ser encontradas na Newberry Library.

Outrossim, possíveis pesquisadores da Coleção Greenlee não devem deixar de consultar o Catálogo Público, pois aí e somente aí, encontrarão um registro completo das obras de História e Literatura Portuguesas da Newberry Library, sem levar em conta a que coleção pertencem. No presente trabalho não são relacionadas nossas obras completas de interesse luso-brasileiro, o que devido à natureza do desenvolvimento de nossa coleção de pesquisa, como um todo, não podemos pretender.

Cumpro dever muito agradável ao reconhecer as generosas doações que a Calouste Gulbenkian, de New York, ofertou a Newberry em anos recentes, permitindo à Coleção Greenlee adquirir muitos livros e impulsionar alguns projetos de pesquisa. Este apoio serviu de muito para tornar a Coleção Greenlee um 
dos mais importantes meios existentes para o estudo da História e da Literatura Portuguesa.

Como uma instituição de pesquisa, os depositários da $\mathrm{New}$ berry exigem que a mesma restrinja o uso de seu acervo aos limites da Walton Street, onde a Coleção Greenlee está à disposição, através dos Serviços Especiais de Coleções. $O$ fornecimento de vários tipos de reproduções fotográficas de parte das obras na Coleção Greenlee é sempre considerado com relação à natureza, condição e disponibilidade geral dos materiais solicitados.

FREDERICK HOLDEN HALL.

Bibliographer . 